\title{
EL CONTRATO DE SEGURO EN LA RESPONSABILIDAD
} EXTRACONTRACTUAL DE LA ADMINISTRACIÓN PÚBLICA: ESTUDIO COMPARADO CON EL DERECHO ESPAÑOL*

\author{
THE INSURANCE CONTRACT IN THE \\ EXTRA-CONTRACTUAL RESPONSIBILITY OF PUBLIC \\ ADMINISTRATION: COMPARATIVE LAW SPAIN - COLOMBIA
}

\author{
ANA MARÍA PALACIO VARGAS $S^{* *}$ \\ Fecha de recepción: 1 de febrero 2020 \\ Fecha de aceptación: 14 de febrero 2020 \\ Disponible en línea: 30 de diciembre 2020
}

Para citar este artículo/To cite this article

Palacio VArgas, Ana María. El contrato de seguro en la responsabilidad extracontractual de la administración pública: Estudio comparado con el derecho español, 53 Rev.Ibero-Latinoam.Seguros, 55-84 (2020). https://doi.org/10.11144/Javeriana.ris53.csre

doi.org/10.11144/Javeriana.ris53.csre

\footnotetext{
Este artículo de investigación es un resumen de la tesis de maestría de la autora realizada en la Universidad de Girona España

** Abogada Pontificia Universidad Javeriana, Magister Derecho de Daños Universitat de Girona. Abogada Senior GHerrera Abogados. Contacto: anamariapalacio018@gmail.com.
} 


\section{RESUMEN}

El seguro de responsabilidad de la Administración Pública, tanto en España como en Colombia, es un contrato típico, es decir, reconocido legalmente. Este tipo de seguro se identifica en sus rasgos esenciales con el seguro de responsabilidad civil, por lo tanto, es un seguro de daños.

En el ordenamiento jurídico español, así como en el colombiano, el aludido contrato de seguro se rige por normas especiales, en atención a que el asegurado es un ente de derecho público. Se advierte que, en uno y otro ordenamiento, se comparten los elementos definitorios de la figurar bajo estudio, lo cual no genera sorpresa, debido a que ambos ordenamientos encuentran su fuente, al menos en la materia, en el derecho francés.

Palabras clave: Administración Pública, contrato de seguro, responsabilidad civil.

\section{ABSTRACT}

Public Administration liability insurance, both in Spain and in Colombia, is a typical agreement, that is, legally recognized. This type of insurance is identified in its essential points with civil liability insurance, therefore it is a damage insurance.

In the Spanish legal system as well as in the Colombian legal system, the mentioned insurance agreement is governed by special rules, insofar as the insured is a public entity. It is noted that in one order and another, the defining elements of the figure under study are shared, this is not strange, because both legal systems find their source, in this field, in French law.

Key words: Public Administration, insurance agreement, civil liability.

\section{SUMARIO}

Introducción. Capítulo I. Justificación del aseguramiento de la responsabilidad extracontractual de la administración pública. Capítulo II. El seguro de responsabilidad de la administración y la indemnización de los daños extrapatrimoniales. 2.1. El perjuicio extrapatrimonial en el derecho colombiano. 2.2. El perjuicio extrapatrimonial en el derecho español. Capítulo III. La acción directa. 3.1. La acción directa en el ordenamiento español. 3.2. La acción directa en el ordenamiento colombiano. Conclusiones. Bibliografía. 


\section{INTRODUCCIÓN}

La Administración Pública como persona jurídica se encuentra proclive a ocasionar daños a través de sus actos u omisiones.

Debido al volumen e impacto de la actividad administrativa son múltiples los daños que se pueden derivar de la misma, implicando la responsabilidad de la Administración, por tal motivo es necesario, o al menos útil, el aseguramiento de la responsabilidad de la Administración a través del contrato de seguro.

Ahora bien, tanto en el ordenamiento español como en el ordenamiento colombiano, la responsabilidad de la Administración Pública se erige bajo los siguientes elementos: (I) Acto u omisión de la Administración Pública (II) Daño antijurídico, entendido como la lesión a un interés jurídico protegido que el perjudicado no está en el deber de soportar, acompañado de un perjuicio (III) Nexo causal entre el acto u omisión de la Administración Pública y el daño.

Se adiciona un cuarto elemento al juicio de responsabilidad de la Administración en el derecho colombiano y es (IV) el título de imputación, a raíz del cual podemos afirmar que en Colombia la responsabilidad puede configurase a partir de un régimen objetivo, pero también subjetivo cuando se trata de la falla del servicio. Por su parte, en España, la responsabilidad de las administraciones públicas será objetiva, prescindiendo del requisito del título de imputación.

Así entonces, el trabajo que a continuación se presenta pretende mostrar la figura del seguro de responsabilidad de la Administración Pública, dentro del marco normativo de Colombia, con un análisis de derecho comparado con el ordenamiento jurídico español. Igualmente, se incluirán, brevemente, las principales razones, tanto económicas como sociales que justifican el aseguramiento de la responsabilidad de administración Pública.

Así entonces, se plantearán dos temas que se consideran de vigente discusión, a saber: (I) El seguro de responsabilidad de la administración y la indemnización de los daños extrapatrimoniales y (II) La acción directa.

El primero se abordará desde la dificultad que resulta para la compañía aseguradora delimitar, dentro de un contrato de seguro de responsabilidad, los perjuicios que deberá pagar a título de indemnización cuando en el sistema judicial existe una proliferación indefinida de categorías de perjuicios extracontractuales. Cuestión que presenta mayores dificultades en el ordenamiento colombiano que en el derecho español, tal como se apreciará más adelante.

Por su parte, la acción directa que se presenta contra el asegurador, sin vincular al asegurado, de quien se predica la responsabilidad, plantea discusión en cuanto a la jurisdicción competente para conocer este tipo de acciones cuando el asegurado es la Administración Pública. 


\section{JUSTIFICACIÓN DEL ASEGURAMIENTO DE LA RESPON- SABILIDAD EXTRACONTRACTUAL DE LA ADMINISTRACIÓN PÚBLICA}

La responsabilidad de la Administración Pública, en palabras de Pavelek, se configura como un instrumento de garantía patrimonial de los ciudadanos frente a los actos dañosos de la Administración ${ }^{1}$.

Así entonces, el perjuicio patrimonial o extrapatrimonial que la Administración Pública cause a un tercero será indemnizado, pues así lo disponen las normas y leyes, tanto del ordenamiento colombiano como del español, esto como expresión del orden establecido por el derecho natural.

Antes de abordar el tema de la justificación del seguro de responsabilidad de la Administración Pública, es conveniente hacer referencia a la justificación económica de la responsabilidad extracontractual, para tal efecto seguiremos los lineamientos trazados por PAPAYANIS ${ }^{2}$, quien indica que las reglas de responsabilidad minimizan los costos sociales. Ahora bien, ¿cuáles son los costes que se reducen?, es una cuestión clave que CALABRES ha contribuido a dilucidar, para el citado autor son tres los tipos de costes sociales, a saber:

(I) Costes primarios: Corresponden a la suma de los daños que efectivamente suceden más el coste de las precauciones.

Estos costes pueden reducirse por medio de dos métodos: A) la disuasión general $o$ método de mercado, el cual consiste en incorporar el coste social dentro del coste privado que para el individuo representa la realización de la actividad. Por lo tanto, a partir de este método, el individuo que realiza la actividad tendrá incentivos para reducir los riesgos y tomar medidas preventivas. B) La disuasión especifica o método colectivo, por medio del cual se prohíbe total o parcialmente una actividad, que por los riesgos que comporta su realización las probabilidades de daño se incrementan.

Al respecto, debemos señalar que coincidimos con la crítica generalizada en torno al segundo método, la cual consiste en poner de presente que la prohibición de ciertas actividades puede generar mayores costes sociales, pues, por el contrario, su ejecución produce altos beneficios para la sociedad, lo cual va de la mano del normal y esperado desarrollo social.

Por lo tanto, el método de mercado, dentro del cual se presentan las reglas de responsabilidad por culpa y de responsabilidad objetiva, a través de las cuales se asignan los costes de los daños a las partes, se considera la mejor forma de reducir los costes primarios.

\footnotetext{
1 PaveleK, Juan Eduardo. El aseguramiento de la responsabilidad de la Administración. Revista de derecho de los seguros privados.

2 PapaYanis, Diego. La responsabilidad civil como asignación de pérdidas. Revista InDret, Barcelona, enero 2014, pp. 9-14.
} 
(II) Costes secundarios: Se derivan de los costes primarios en la medida en que estos recaigan en los individuos que tienen menor capacidad para soportar dichos costes ${ }^{3}$.

Se conocen dos métodos para reducir los costes secundarios:

A. La dispersión de los daños entre las personas y el tiempo. Esta dispersión se logra por medio del seguro obligatorio o voluntario, a partir del cual el siniestro se cubre con la suma que una colectividad ha aportado a un mismo fondo.

Claro que a través de este método se presenta el conocido problema de moral hazard o riesgo moral, debido a que los individuos al saber que se encuentran asegurados reducen el nivel de sus precauciones.

B. La distribución de los daños. Este método implica realizar una distribución conforme a los recursos económicos de los que dispongan las partes, por lo cual las medidas que deban adoptarse serán distintas entre unos y otros, en función de su capacidad contributiva.

Es así como, por vía de ejemplo, algunos ordenamientos jurídicos consagran la facultad en cabeza del juez de fallar conforme a la equidad, donde se tienen en cuenta las condiciones tanto económicas como personales del agente dañador y de la víctima ${ }^{4}$.

(III) Costos terciarios: Son aquellos asociados a los costes de administración propios de cualquier sistema de gestión de daños. Así entonces, si se decidiera adoptar un sistema de responsabilidad civil, los costes terciarios estarían asociados a costes de litigio, entre otros.

Es indiscutible la relación compleja que vincula a los tres tipos de costes, al punto tal que la reducción de uno de ellos implicaría el aumento del otro, lo cual no significa que no sea posible llevarlos a un punto de equilibrio razonable.

Así entonces, y a pesar de que los demás métodos existentes para reducir los costes sociales puedan ser valiosos en específicas situaciones, consideramos que es el sistema de la responsabilidad civil y del seguro los que mejor equilibran dichos costes. Por lo tanto, en ello encuentra la responsabilidad extracontractual su justificación económica y social.

En adición a lo anterior, la responsabilidad civil, como ya se ha indicado, cumple con una función reparadora o indemnizatoria, en estricto sentido, no obstante, considera-

\footnotetext{
3 PAPAYANIS ejemplifica los costos secundarios afirmando que: "En términos más familiares, es evidente que hacer recaer un daño de 1.000 sobre 10 personas con capacidades contributivas similares reduce el bienestar social menos que hacerlo recaer sobre una de ellas. Asimismo, hacer recaer la pérdida de 1.000 sobre una persona que gana el salario mínimo impacta en su bienestar mucho más de lo que impactaría sobre el bienestar de una persona extremadamente rica". PAPAYANIS, Diego. La responsabilidad civil como asignación de pérdidas, Revista InDret, Barcelona, enero 2014, p. 11.

4 Argentina, Código Civil, art. 907. "Cuando por los hechos involuntarios se causare a otro algún daño en su persona y bienes, sólo se responderá con la indemnización correspondiente, si con el daño se enriqueció el autor del hecho, y en tanto, en cuanto se hubiere enriquecido. Los jueces podrán también disponer un resarcimiento a favor de la víctima del daño, fundados en razones de equidad, teniendo en cuenta la importancia del patrimonio del autor del hecho y la situación personal de la víctima" (se resalta).
} 
mos que no se limita a ella y, muy por el contrario, se extiende en el campo previo a la indemnización hasta llegar a la prevención, todo esto en apoyo de la obra del doctor JARAMILLO, quien propende por reconocer la doble función de la responsabilidad civil, tanto indemnizatoria como preventiva. Haciendo mayor énfasis en esta última, el citado doctrinante señala que se trata de una concepción más humanística, consecuente y conectada con la dignidad humana, toda vez que si el propósito cardinal del Derecho es el hombre (la referida dignidad), mejor aún su sistemática protección, no puede desconocerse que sus intereses se salvaguardan mediante la prevención y la evitación del daño ${ }^{5}$.

Ahora bien, tanto los particulares como la Administración Pública buscan blindar su patrimonio ante la eventual obligación indemnizatoria que orbite in capitis por sus actos $\mathrm{u}$ omisiones, por tal razón se contratan los seguros de responsabilidad cuya función es mitigar, minimizar y proteger de los efectos patrimonialmente negativos que surgen de una deuda de responsabilidad ${ }^{6}$. En todo caso, siguiendo a GRIJALBA, contratar un seguro es un acto justificado por la actitud que se tiene ante el riesgo, pues se prefiere pagar una cantidad determinada dentro de un tiempo igualmente determinado, que constituye la prima, que afrontar en su día un riesgo, es decir un evento incierto ${ }^{7}$, actitud común pues, como es sabido, la mayoría de las personas presentan aversión al riesgo.

Por supuesto la protección otorgada por el seguro tendrá el cubrimiento que se haya pactado en el contrato y que permitan la ley y las buenas costumbres. Por tal razón, y por vía de ejemplo, no es posible, ni en Colombia y tampoco en España, asegurar los daños causados con dolo, así como tampoco habrá una protección total del patrimonio, pues en ambos ordenamientos el asegurado responderá con su propio patrimonio por el costo del siniestro, figura que se conoce en España como franquicia y en Colombia se le denomina deducible.

No obstante, más allá de la protección del patrimonio del asegurado, el seguro encuentra una justificación mayor en la protección indemnizatoria del tercero perjudicado, más que en la tradicional función de conservar el patrimonio del asegurado, que según ha señalado parte de la doctrina, ha quedado en segundo lugar ${ }^{8}$.

Continuando en apoyo con PAPAYANIs ${ }^{9}$, en los sistemas de responsabilidad civil con culpa, las víctimas aversas al riesgo, al ser los agentes residuales en este tipo de siste-

\footnotetext{
5 Jaramillo Jaramillo, Carlos Ignacio. Los deberes de evitar y mitigar el daño. Editorial Temis, Pontificia Universidad Javeriana, Bogotá, 2013, p. 32.

${ }^{6}$ Veiga Copo, Abel B. Tratado del contrato de seguro. Editorial Aranzadi, S.A.U., Navarra, 2017, p. 394. Este mismo sentido se lo ha dado la jurisprudencia española al señalar: "El seguro de responsabilidad civil trata de proteger el patrimonio del asegurado, cubriendo el riesgo de su minoración, dentro de los límites del contrato, cuando aquél tenga que indemnizar a terceros, por haberse producido el siniestro pactado”. Tribunal Supremo de España, sentencia de junio 15 de 1995.

7 Grijalba López, Juan Carlos. La compañía aseguradora en el procedimiento de responsabilidad patrimonial. Dialnet, DS: Derecho y salud, ISSN 1133-7400, Vol. 21, №. Extra-1, 2011 (Ejemplar dedicado a: XIX Congreso "Derecho y Salud"), p. 156.

${ }^{8}$ Tribunal Supremo de España, sentencia de diciembre 26 de 1986.

9 PapaYanis, Diego. La responsabilidad civil como asignación de pérdidas, Revista InDret, Barcelona, enero 2014, pp. 31-32.
} 
mas, tenderán a tomar mayores precauciones para evitar daños llegando a niveles tan altos que sean ineficientes, alejándose del nivel óptimo de precaución.

Por su parte, en los sistemas de responsabilidad objetiva, los agentes dañadores con aversión al riesgo, al ser los agentes residuales, tomarán medidas excesivas y, por ende, ineficientes.

Lo anterior se resuelve a través de un sistema de seguros, dentro del cual tanto las víctimas como los agentes dañadores que sean aversos al riesgo contratarán un seguro y así disminuirán la incertidumbre dejando de tomar medidas excesivas e ineficientes.

Ahora bien, respecto del aseguramiento de la Responsabilidad de la Administración, debe recordarse que, en un principio, la Administración no contrataba el seguro de responsabilidad, debido a que operaba la figura del autoseguro, según la cual, como lo explica Huergo, la Administración no necesita pagar los servicios de un asegurador que la integre en una comunidad de riesgos, porque ella misma, al llevar a cabo múltiples actividades no conectadas entre sí (por ejemplo, múltiples obras o múltiples actos médicos independientes en el sentido de que la producción de un siniestro en uno de ellos no conlleva necesariamente un siniestro en otro), reúne esa "masa de operaciones uniformes" que constituye la base del seguro ${ }^{10}$.

Al citado argumento se le suma el hecho de que el pago de todas las primas sería equivalente a las indemnizaciones que debería pagar la Administración, añadiendo los costes de gestión, lo cual, según dicen algunos, resultaría antieconómico pues el costo total de tener en un seguro sería superior al costo de pagar cada indemnización.

No obstante, nos inclinamos por afirmar que el aseguramiento de la responsabilidad de la Administración Pública deriva en mayores beneficios, tanto económicos como sociales, para la Administración y, en especial, para sus administrados.

Así entonces, cuando es la Administración Pública la que actúa como asegurado, es decir, en un sistema hetero-compositivo como lo denomina GAMERO CASADO ${ }^{11}$ en el que el aseguramiento de la responsabilidad de la Administración implica el desplazamiento del riesgo que conlleva la actividad administrativa, no se contrarían los principios constitucionales o legales de ninguno de los ordenamientos objeto del presente estudio, por el contrario, se han encontrado razones de suficiente peso para propender al aseguramiento de la responsabilidad de la Administración Pública, a saber:

(I) Estabilidad presupuestaria, toda vez que, al inicio de cada periodo fiscal, la Administración dispone de un presupuesto para el pago de la prima, con independencia de la cantidad de siniestros o del costo de las indemnizaciones. Por lo tanto, una indemnización que resulte altamente costosa no generará desequilibrio financiero pues

\footnotetext{
${ }^{10}$ Huergo Lora, Alejandro. El seguro de responsabilidad civil de las Administraciones Públicas, Universidad de Oviedo, Working Paper No. 150. Barcelona, julio de 2003.

11 Gamero CASAdo, Eduardo. "El aseguramiento de la responsabilidad patrimonial de la Administración", capítulo IV del Tomo I, p. 36. En: La responsabilidad patrimonial de la Administración Pública. Estudio General y hábitos sectoriales. Ed. Tirant lo Blanch. Director Tomás Quintana López. Coordinadora Anabelén Casares Marcos.
} 
deberá cubrirse por la aseguradora. Lo que redunda en una protección del patrimonio de la Administración frente al pago de la eventual indemnización.

(II) Se le otorga una mayor garantía para el ciudadano frente al pago de la indemnización, pues ya no ha de depender de los recursos con los que la Administración disponga para el pago de los siniestros, que a pesar de que esta siempre es solvente, a través del seguro se garantiza una mayor celeridad en el pago de la indemnización.

(III) Otra razón de tipo práctico que menciona GRIJALBA es la presión que ejercen determinados sectores de la Administración Pública, cuya actividad es más proclive a causar daños, por vía de ejemplo la actividad sanitaria, de infraestructura, de seguridad, entre otras ${ }^{12}$.

Adicionalmente, en Colombia se ha establecido, vía constitucional, la función social de la actividad aseguradora ${ }^{13} \mathrm{y}$, en concreto, la Corte Constitucional ${ }^{14}$ ha extendido dicha función social al seguro de responsabilidad civil, lo cual impacta con mayor fuerza en los planteamientos expuestos sobre la justificación del seguro.

En síntesis, el seguro de responsabilidad de la Administración Pública encuentra su sustento en el deber de responderle a la expectativa social con fundamento en el óptimo deseable de la gestión fiscal, en miras a la prevalencia del interés general.

\footnotetext{
12 GRIJAlba López, Juan Carlos. La compañia aseguradora en el proceso de responsabilidad patrimonial, Mesas de Trabajo, Volumen 21, Extraordinario XIX Congreso.

13 Constitución Política de Colombia. Art. 335. "Las actividades financiera, bursátil, aseguradora y cualquier otra relacionada con el manejo, aprovechamiento e inversión de los recursos de captación a las que se refiere el literal d) del numeral 19 del art. 150 son de interés público y sólo pueden ser ejercidas previa autorización del Estado, conforme a la ley, la cual regulará la forma de intervención del Gobierno en estas materias y promoverá la democratización del crédito" (Se resalta).

14 "Desde la perspectiva de los beneficios sociales que su ejecución implica, puede afirmarse que aspectos tan importantes como la salud de las personas, su integridad corporal, el patrimonio, la estabilidad familiar, la capacidad laboral y económica, así como las actividades económicas generalmente efectuadas, quedan amparados ante los distintos peligros que pueden afectarlos. Además, la acción de las aseguradoras trae consigo la configuración de una conciencia en la comunidad, cada vez más generalizada frente a distintos riesgos, de la necesidad de adoptar conductas de índole previsiva dirigidas a evitar la concreción de los riesgos o a reducir las consecuencias del siniestro, resultado que en el ámbito social es al mismo tiempo trascendente y necesario". (Corte Constitucional de Colombia, sala plena, sentencia de 28 de abril de 1999, M.P. Marta Victoria Sáchica de Moncaleano).

En el mismo sentido se ha añadido que:

"Esta previsión del riesgo se fundamenta en el propósito de cumplir con la función social consistente no sólo en proteger el patrimonio del asegurado o amparar a los beneficiarios del seguro por los daños que ocasionó la ocurrencia del hecho riesgoso cubierto (que ya es mucho), sino en proteger la confianza y la seguridad que reclama la economía de mercado y en general el desenvolvimiento de la vida social y económica del mundo contemporáneo, intangibles valiosos propios a toda sociedad con un estadio medianamente avanzado de civilización, y por los cuales los seguros en general, representan aspectos vitales en las relaciones humanas. (...) Tanto así y más se predica respecto del contrato de seguro de responsabilidad civil. Esta figura negocial tiene por estructura y finalidad específica, condiciones que hacen de su función social y de la buena fe de las partes del contrato, elementos vitales, pues el cumplimiento o no 120 de las obligaciones de las partes está íntimamente vinculado con el resarcimiento o no de la víctima de un hecho lesivo cubierto por el seguro". CORTE COnstitucional de Colombia, sala plena, sentencia de 17 de junio de 2009, M.P. Juan Carlos Henao Pérez.
} 


\section{EL SEGURO DE RESPONSABILIDAD DE LA ADMINIS- TRACIÓN Y LA INDEMNIZACIÓN DE LOS PERJUICIOS EXTRAPATRIMONIALES}

Como es sabido el daño, entendido como la lesión a un interés protegido jurídicamente, se refleja en dos tipos de perjuicios, patrimoniales o extrapatrimoniales, según el interés jurídico que impacte.

Un perjuicio será patrimonial cuando lesione la órbita económica de la víctima, por la disminución de su patrimonio, lo que se denomina daño emergente, o por la pérdida de la aptitud de generar ingresos, conocido como lucro cesante.

En contraste, un perjuicio será extrapatrimonial cuando su impacto se dé en la esfera personal de la víctima, es decir cuando "afecte valores trascendentes del individuo como ser humano" 15 .

Es claro, en todo caso, que de un único hecho dañoso que produce un daño determinado pueden derivarse, de forma simultánea o sucesiva, tanto perjuicios patrimoniales como extrapatrimoniales.

Siguiendo a los doctrinantes españoles MACIÁ y GóMEZ, el perjuicio extrapatrimonial puede definirse en función de su diferencia con el perjuicio patrimonial, como aquel que "implica una reducción del nivel de utilidad que ni el dinero, ni bienes intercambiables por éste, pueden llegar a compensar"16 y no lo puede llegar a compensar por la simple razón de que no tiene un equivalente dinerario que pertenezca a partida alguna dentro del patrimonio.

Ahora bien, la tipología del perjuicio patrimonial no presenta inconvenientes, sin embargo, no puede afirmarse lo mismo de los daños extrapatrimoniales, categoría que ha venido presentando un importante desarrollo. Tradicionalmente se había considerado que el perjuicio extrapatrimonial tenía identidad plena con el daño moral, como si ambos conceptos fueran sinónimos. Doctrinantes como MinozzI ${ }^{17}$ han afirmado que entender que el perjuicio extrapatrimonial sea correspondiente al daño moral es erróneo, toda vez que existen daños que no generan perjuicios patrimoniales, pero

\footnotetext{
15 Weingarten, Celia. “Manual de derecho de daños", La Ley, Buenos Aires, 2010, p. 27. Se considera que el perjuicio extrapatrimonial se identifica con la noción de perjuicio inmaterial, la cual se puede definir por contraposición a la noción de perjuicio material, es decir, el daño inmaterial es: "La pérdida que no es daño en el patrimonio de una persona, en su riqueza o en sus ingresos y que no es, por lo tanto, susceptible de ser cuantificada de algún modo económicamente objetivo por referencia a un mercado" (W.V.H. Rogers, Comparative Report, en: W.V.H. Rogers (ed.), Damages for Non-Pecuniary Loss in a Comparative Perspective (2001) 246 (num. 2) C.f. También U. Magnus, Alemania, Petl Damages, nm. 40. En: "Principios de Derecho Europeo de la Responsabilidad Civil”, traducción de REDPEC, Coord. Por Martín-Casals, Miquel, Editorial Aranzadi S.A., 2008, p. 62).

16 Maciá Gómez, Ramón. Concepto y evaluación del daño moral, 19 de enero de 2009. http://www. ramonmacia.com/el-dano-moral-concepto-elementos-y-valoracion/, Gómez Pomar, Fernando. Daño moral, Indret: Revista para el Análisis del Derecho, ISSN 1698-739X, №. 1, 2000.

17 En Peirano, Jorge. Responsabilidad extracontractual, Ed. Temis, Bogotá, 1981, p. 377.
} 
tampoco se identifican con el perjuicio moral, tal es el caso del dolor físico causado por una herida.

De esta manera resulta claro que el perjuicio extrapatrimonial es el género dentro del cual se encuentra el perjuicio moral, que se define para WEINGARTEN como aquel que se causa tras la vulneración del derecho a la integridad de los sentimientos como valor en sí mismo, trasformados en valor jurídico ${ }^{18}$.

Por otra parte, LAGOMARSINO sostiene que los sentimientos conforman un aspecto trascendente en la vida del ser humano, que por antonomasia busca la felicidad y cuando se lesionan producen un dolor muy particular en cada individuo cuya intensidad depende del valor que cada persona le otorgue ${ }^{19}$.

Desde otra arista, señala VELÁSQUEZ, haciendo una reflexión sobre la literatura comparada, que el daño moral comprende dos aspectos: "de un lado el dolor físico producido por lesiones corporales y enfermedades y también la tristeza, amargura o angustia moral de haber padecido una lesión física o la muerte de un ser querido" ${ }^{20}$, posición que genera dudas pues entendemos que la lesión corporal, al estar absolutamente ligada al dolor físico, en su conjunto conforman el daño o perjuicio corporal, de naturaleza extrapatrimonial, y considerar dicho dolor físico como daño moral desdibujaría su esencia y generaría mayor confusión, por vía de ejemplo, en el caso del suministro de analgésicos al paciente, se cuestionaría si ha sufrido o no un daño moral al dejar de padecer un dolor físico, cuestión que carece de sentido, toda vez que independientemente del dolor físico que se perciba o no, hay una lesión corporal y adicional a ella, un perjuicio moral.

En virtud de lo anterior, no es dable equipararse el dolor físico al daño moral, o sostener que el dolor físico es una expresión del daño moral.

De esta forma, el perjuicio moral no es más que el sentimiento de dolor, angustia, aflicción o tristeza que padece una persona como consecuencia de un determinado hecho.

En la misma línea, debe señalarse que, además del perjuicio moral, dentro de la categoría de los perjuicios extrapatrimoniales, se han incorporado otros como el daño a la vida de relación, el daño a la salud, el perjuicio fisiológico, la pérdida de calidad de vida, la vulneración a derechos de la personalidad, entre otros. Las anteriores subcategorías de perjuicios dentro del género del perjuicio extrapatrimonial han convivido de forma simultánea generando confusión y son un reflejo de la desarmonización del sistema.

A continuación, se detallará la evolución que han tenido estas categorías en el ordenamiento colombiano.

\footnotetext{
18 Weingarten, Celia. Manual de derecho de daños, La Ley, Buenos Aires, 2010, p. 76.

19 Lagomarsino, Ismael A. "Consorcio de Propietarios Juncal 2259/61", La Ley, 1997. En Weingarten, Celia. Manual de derecho de daños, La Ley, Buenos Aires, 2010, p. 76.

20 Velásquez Posada, Obdulio. Itinerario Jurisprudencial del Daño Moral en Colombia. Revista Responsabilidad Civil y del Estado No. 26, pp. 65-67.
} 


\subsection{El perjuicio extrapatrimonial en el derecho colombiano}

En Colombia el perjuicio extrapatrimonial se reconoció por primera vez en la sentencia de julio 21 de 1922 proferida por la Corte Suprema de Justicia, a través de la cual se indicó que en el caso de daño moral la indemnización tenía por objeto reparar el dolor sufrido llenando el vacío que produjo el quebranto moral del demandante ${ }^{21}$.

En una posterior ocasión, la Corte Suprema de Justicia, en sentencia de abril 23 de 1941 señaló que: "El daño moral es la lesión del patrimonio moral propiamente dicho o del patrimonio afectivo". Adicionalmente, en la referida sentencia se hace una distinción entre perjuicios objetivados y los no susceptibles de objetivación, respecto de los primeros se indica que son aquellos que pueden fácilmente repararse por sus repercusiones económicas, se cita el ejemplo del perjuicio que sufre una persona en su patrimonio por la pérdida de su crédito causada por actos difamatorios, frente a tal caso señala la Corporación que se trata de un "daño tangible, estimable con relativa facilidad, concretable en cifras numéricas". Raciocinio del cual nos apartamos por considerar que se está confundiendo el daño con el perjuicio, pues de un mismo hecho dañoso, como fue la difamación, surgen varios perjuicios, entre ellos unos de tipo patrimonial, en este caso la pérdida del crédito, y otros de tipo extrapatrimonial como es el perjuicio moral, por lo tanto, se considera que el perjuicio moral, en todos los casos es intangible pues se refiera a la esfera de los sentimientos, con indiferencia a que converjan otro tipo de perjuicios que encuentren equivalente en el dinero.

Ahora bien, citando a DE CUPIS cuando señala que: “(...) es imposible y repugna a la razón y al sentimiento, reducir a dinero el interés relativo a bienes como el honor, la integridad física y todos los de esta índole"22, debe afirmarse que a pesar que el perjuicio moral no pueda ser indemnizado, en estricto sentido, esto no implica que no pueda y deba ser compensado con una determinada suma de dinero, que es la mejor forma que el derecho ha encontrado para reparar los daños dentro del marco de la responsabilidad civil y del Estado.

En resientes pronunciamientos la Corte Suprema de Justicia ha reafirmado que "el daño moral se configura como una típica especie de daño no patrimonial consistente en quebranto de la interioridad subjetiva de la persona y, estricto sensu, de sus sentimientos y afectos"23. Definición a la que nos adherimos.

Por su parte, la jurisdicción Contenciosa Administrativa, en cabeza del Consejo de Estado también ha reconocido el perjuicio moral ${ }^{24}$, a la par de otros perjuicios de índole extrapatrimonial, tal como se verá en notas posteriores.

\footnotetext{
${ }^{21}$ Corte Suprema de Justicia de Colombia, Sala de Casación Civil, 21 de Julio de 1922, M.P. Tancredo Nannetti, Gaceta Judicial, Tomo XXIX No. 1515, p. 220.

22 De CupIs, Adriano. Teoría General de la Responsabilidad Civil. El Daño, 2 ed. Barcelona: BOSCH, Casa Editorial, 1975, p. 364.

23 Corte Suprema de Justicia de Colombia, Sentencia septiembre 18 de 2009.

24 El Consejo de Estado colombiano ha definido el daño moral como el "menoscabo de derechos de bienes extrapatrimoniales jurídicamente protegidos" (CONSEJO DE ESTADO, Sala de lo Contencioso Administrativo, Sección Tercera, 11 de diciembre de 1992). Se reitera, al respecto de la citada definición, lo señalado en precedencia sobre el entendimiento de que el perjuicio extrapatrimonial es el género y el
} 
Por otro lado, en Colombia se ha desarrollado la figura del perjuicio fisiológico, como otra especie del perjuicio extrapatrimonial. El primer pronunciamiento al respecto fue en el año de 1985 por el Tribunal Superior de Medellín ${ }^{25}$ en donde lo califica como una tercera categoría adicional al daño moral. Posteriormente, en el año de 1993, el Consejo de Estado reconoce el perjuicio fisiológico, y lo definió, siguiendo a TAMAYO JARAMILLO como "dolor físico que en un momento determinado pueda sufrir la víctima de un accidente" 26 .

No obstante, en sentencia de julio 19 de 2000 proferida por el Consejo de Estado, se introdujo la figura del daño a la vida de relación y se le otorgó un tratamiento asimilable al del daño fisiológico, pero con un entendimiento más extenso en el sentido de no limitarlo al dolor corporal, para incluir la alteración a la vida de relación de las personas, la cual "no consiste en la lesión en sí misma, sino en las consecuencias que, en razón de ella se producen en la vida de relación de quien la sufre" es decir, el padre que pierde una pierna no solo padece del dolor físico sino que, también, ve alterada sus relaciones familiares y sus hábitos, por esta razón el daño a la vida de relación no solo se limita a la víctima sino a las personas cercanas a esta, que sufren también de una alteración negativa en su vida ${ }^{27}$.

Por su parte, la jurisdicción civil, encabezada por la Corte Suprema de Justicia reconoció el daño a la vida de relación, definiéndolo como:

"La disminución o deterioro de la calidad de vida de la víctima, en la pérdida o dificultad de establecer contacto o relacionarse con las personas o cosas, en orden a disfrutar de una existencia corriente, como también en la privación que padece el afectado para desplegar las más elementales conductas que en forma cotidiana o habitual marcan su realidad" (Se resalta) ${ }^{28}$.

Continuando con el desarrollo que ha sufrido la categoría de perjuicio extrapatrimonial en la jurisdicción Contenciosa Administrativa, debe señalarse que en el año 2007 el Consejo de Estado introdujo un nuevo concepto dentro del cual agrupó las categorías de daño fisiológico y daño a la vida en relación, el cual denominó "alteración a las condiciones de existencia”, figura que según considera la aludida Corporación:

“...abarca no solo la relación de la víctima con el mundo exterior, sino, de manera más general, esos cambios bruscos y relevantes a las condiciones de una persona en cuanto tal y como expresión de la libertad y del albedrío atributos esenciales a la dignidad humana”29.

Nuevamente, en años posteriores, el Consejo de Estado incorporó en la jurisprudencia la noción de "daño a la salud". Al respecto, en providencia de agosto 28 de 2014 se indicó:

\footnotetext{
perjuicio moral es una de sus especies.

25 Tribunal Superior de Medellín el 22 de marzo de 1985, mediante fallo con ponencia de la Dra. Beatriz Quintero Prieto.

${ }^{26}$ Consejo de Estado de Colombia, Sala de lo Contencioso Administrativo, Sección Tercera, Sentencia mayo 6 de 1993. M.P. Julio César Uribe Acosta.

27 Consejo De Estado de Colombia, Sala de lo Contencioso Administrativo, Sección Tercera, sentencia de julio 19 de 2000. C.P. Alier Eduardo Hernández Henríquez.

28 Corte Suprema de Justicia de Colombia, Sala de Casación Civil, sentencia de mayo 13 de 2008.

29 Consejo de Estado de Colombia, Sala de lo Contencioso Administrativo, Sección Tercera, sentencia de 15 de agosto de 2007.
} 
“...se puede decir que se avanza a una noción más amplia del daño a la salud, que se pasa a definir en términos de alteración psicofísica que el sujeto no tiene el deber de soportar, sin importar su gravedad o duración y sin que sea posible limitar su configuración a la existencia de certificación sobre la magnitud de la misma”30.

Adicionalmente, se ha introducido una nueva categoría conocida como: "la vulneración de bienes constitucionales y convencionalmente protegidos". En palabras de María Juliana VALDIVIESO, esta "tiene por objeto la protección a los derechos fundamentes específicamente en lo que tiene que ver con dignidad humana y las garantías derivadas de la misma, buscando con estas la materialización del principio de reparación integral"'31.

Respecto de esta nueva categoría, el Consejo de Estado en sentencia de agosto 28 de 2014 hizo mención del "daño a otros bienes constitucionales protegidos", frente a lo cual señaló:

"Se trata de reconocer, aún de oficio, la afectación o vulneración relevante de bienes o derechos convencional y constitucionalmente amparados. Procederá siempre y cuando, se encuentre acreditada dentro del proceso su concreción y se precise su reparación integral. Se privilegia la compensación a través de medidas reparatorias no indemnizatorias a favor de la víctima directa y a su núcleo familiar más cercano".

Debe señalarse que el último fragmento de la providencia en cita, al señalar que frente a los daños a bienes constitucionales protegidos se privilegia la compensación antes que la indemnización da a pensar, erróneamente, que se trata de una categoría externa a la responsabilidad civil y del Estado, pues como ya se ha advertido, el daño, en puridad, se debe indemnizar y la mejor forma para hacerlo es a través de una suma de dinero $^{32}$, por lo tanto todas aquellas medidas reparatorias no indemnizatorias se hallan fuera del marco de la responsabilidad civil.

No obstante, es claro que el daño por la vulneración de bienes constitucionales y convencionalmente protegidos es una figura que se encuentra cobijada e inmersa dentro de la responsabilidad civil y del Estado ${ }^{33}$.

Ahora bien, el Consejo de Estado colombiano, en reciente fallo de febrero 21 de 2018 indicó que el daño causado por la vulneración de bienes constitucionales y conven-

\footnotetext{
30 Consejo de Estado de Colombia, Sala de lo Contencioso Administrativo, Sección Tercera, Sentencia de agosto 28 de 2014, M.P. Dra. Stella Conto Díaz del Castillo.

31 VAldivieso, María Juliana. Asuntos: Legales “¿Cómo se clasifica el perjuicio inmaterial en Colombia, actualmente?", 30 de enero de 2019 https://www.asuntoslegales.com.co/consultorio/como-se-clasifica-elperjuicio-inmaterial-en-colombia-actualmente-2821836

32 Claro que es necesario advertir que en los Principio Europeos de la Responsabilidad Civil en el art. 10:104 sobre la reparación en forma específica se menciona: "En lugar de indemnización, el dañado puede reclamar la reparación en forma específica en la medida en que esta sea posible y no excesivamente gravosa para la otra parte". Esta reparación en forma específica se ha dado especialmente cuando se ha vulnerado el derecho a la honra y se expresa una disculpa pública.

33 "En consecuencia, se reitera que una vez que el juez de lo contencioso administrativo encuentre probado que el derecho fundamental a la libertad de una persona ha sido vulnerado como consecuencia de una decisión judicial, lo que constituye un daño antijurídico a la luz del art. 90 de la C.P, debe ordenar su reparación”. Consejo de Estado de Colombia, Sala de lo Contencioso Administrativo, Sección Tercera, sentencia de febrero 21 de 2018, C.P. Jaime Orlando Santofimio Gamboa.
} 
cionalmente protegidos' se subsume dentro del daño moral para efectos de su indemnización ${ }^{34}$, No obstante, en este punto también debe tenerse en cuenta la sentencia de Unificación Jurisprudencial del 28 de agosto de 2014 en la cual se establece que ante estos daños no habrá una reparación dineraria, solo de forma excepcional podrá reconocerse 100 smlmv.

Resulta claro que el daño causado por la vulneración de bienes constitucionales y convencionalmente protegidos en el ordenamiento colombiano, debe tener el mismo alcance y entendimiento que tiene en el ordenamiento español, es decir, ser considerado como daño y no como perjuicio, lo cual implica que la vulneración a un bien o derecho constitucional puede derivar tanto en perjuicios patrimoniales como extrapatrimoniales, por lo tanto es incorrecto afirmar que se encuentra dentro de esta última categoría. Así mismo, y partiendo de que todo daño indemnizable debe estar acompañado por un perjuicio, resulta claro que el perjuicio que se genera a raíz de este tipo de daños es un perjuicio moral ${ }^{35}$.

Tenemos entonces como panorama general que, por un lado, la Corte Suprema de Justicia en sentencia del 5 de agosto de 2014, reconoció como categorías del perjuicio extrapatrimonial lo siguientes: (I) El daño moral(II) El daño a la vida en relación (III) La vulneración a los derechos humanos fundamentales que gozan de especial protección. Por otro lado, el Consejo de Estado, determinó en sentencia de agosto 28 de 2014 que los perjuicios extrapatrimoniales comprenderían los siguientes: (I) El daño moral (II) Daño a la salud (III) La afectación grave a los bienes constitucional y convencionalmente protegidos ${ }^{36}$.

\subsection{E1 perjuicio extrapatrimonial en el ordenamiento jurídico español}

En España, el perjuicio extrapatrimonial reviste las mismas características que en el ordenamiento colombiano pues se deriva de la doctrina universal ${ }^{37}$. Por otra parte, el problema evidenciado en el derecho colombiano sobre la proliferación desestructura-

\footnotetext{
34 "Al respecto, estima la Sala que lo solicitado inicialmente, debe estudiarse bajo la óptica del daño por la vulneración de bienes constitucional y convencionalmente protegidos, por lo tanto, revisando las pruebas allegadas al proceso, se puede concluir que dicha petición se subsume dentro de lo concedido por daños morales en la presente providencia, pues en dicho acápite le fue reconocido la congoja, el sufrimiento, el deterioro familiar y los cambios, que, per se, evidentemente causa la privación de la libertad de una persona”. Consejo DE Estado de Colombia, Sala de lo Contencioso Administrativo, Sección Tercera, sentencia 21 de febrero de 2018, C.P. Jaime Orlando Santofimio Gamboa.

35 Por lo tanto, "que el perjuicio no patrimonial puede ser por ofensa a la honra o a la dignidad personal o causando dolor o molestia abriendo así la posibilidad de otros daños extramatrimoniales diferentes a la moral" Corte Suprema de Justicia de Colombia, Sala de Casación Civil, sentencia 13 de mayo de 2008, M.P: Cesar Julio Valencia Copete.

36 VAldivieso, María Juliana. Asuntos: Legales “¿Cómo se clasifica el perjuicio inmaterial en Colombia, actualmente?", 30 de enero de 2019 https://www.asuntoslegales.com.co/consultorio/como-se-clasifica-elperjuicio-inmaterial-en-colombia-actualmente-2821836.

37 El daño extrapatrimonial o inmaterial, para el derecho español es aquel que "...no comporta una disminución del patrimonio (daño no patrimonial)" "Principios de Derecho Europeo de la Responsabilidad Civil”, traducción de REDPEC, Coord. Por Martín-Casals, Miquel, Editorial Aranzadi S.A., 2008, p. 62.
} 
da de categorías de perjuicio extrapatrimonial no se encuentra presente en el derecho español, toda vez que cualquier tipo de perjuicio sin necesidad de encajarlo en categorías confusas deberá ser indemnizado, siempre que cumpla con los requisitos establecidos en las leyes 39 de 2015 y 40 de 2015, es decir que sea un daño (I) Efectivo (II) Evaluable económicamente (III) Individualizado con relación a una persona o grupo de personas y, desde luego, (IV) Antijurídico.

Por otra parte, nos orienta la visión sobre los perjuicios reconocidos en el ordenamiento español el texto contenido en el preámbulo de la Ley 25 de 2015, por la cual se incorpora el sistema de valoración de baremos en España, dentro del cual se señala:

"El principio de reparación integral de los daños y perjuicios causados no es efectivo en toda su dimensión, provocando situaciones injustas y en ocasiones dramáticas, con una pérdida añadida de calidad de vida, cuando además, ya se ha sufrido un daño físico, psíquico y moral, y que impone el deber al legislador de encontrar las formas idóneas que garanticen el cumplimiento de tan importante principio"38. (se resalta).

Texto que nos parece absolutamente claro en cuanto a los perjuicios que deben ser reconocidos dentro de la categoría de perjuicios extrapatrimoniales, desde luego, sin restringirse o complicarse con denominaciones confusas, pues en todo caso será indemnizado todo perjuicio que cumpla con los precitados requisitos que, al final, no redundarán en categorías distintas al perjuicio moral, perjuicio corporal -tanto físico como psíquico- y en la pérdida de calidad de vida.

Así entonces, continuaremos con una breve exposición de lo que se considera debe ser el esquema del daño y del perjuicio.

A menudo se entiende que el daño -lesión de un interés jurídico protegido- se divide en (I) Daño a las personas (II) Daño a las cosas, sin embargo, en puridad, el daño es único e incategorabilizable, toda vez que todo daño debe, necesariamente, recaer sobre la persona, por lo tanto si se daña una cosa que pertenece a determinado individuo se está infligiendo daño a la persona, y se tratará de un perjuicio patrimonial, aunque en determinadas y específicas situaciones también podrá comportar un perjuicio extrapatrimonial.

De esta manera, consideramos que el daño a la persona se puede derivar en: (I) Perjuicio patrimonial: 1.1. Daño emergente 1.2. Lucro cesante (II) Perjuicio extrapatrimonial: 2.1. Perjuicio moral 2.2. Perjuicio corporal (físico o psíquico). No se incorporan las demás categorías, debido a que las estimamos redundantes, y por tal razón pueden resultar en daños punitivos ${ }^{39}$.

\footnotetext{
38 España, Ley $\mathrm{N}^{\circ} 35 / 2015$, de 22 de septiembre, de reforma del sistema para la valoración de los daños y perjuicios causados a las personas en accidentes de circulación.

Publicado en: «BOE» núm. 228, de 23 de septiembre de 2015, pp. 84473 a 84979 (507pp.).

39 "El daño punitivo tiene como propósito castigar a quien produce un mal y disuadir tanto al causante del perjuicio como a otros posibles infractores de repetir la misma acción dañina" Flórez FernáNDEZ, José Gregorio. "El daño y la responsabilidad en el derecho norteamericano”, Universidad Externado de Colombia, Bogotá, 2001, pp. 146-182.

Cabe advertir que en Colombia no están reconocidos los daños punitivos, el derecho colombiano es claro al señalar que la indemnización tiene como finalidad dejar a la víctima en la situación anterior, sin que de modo alguno pueda considerarse como fuente de enriquecimiento.
} 
Así las cosas, consideramos que el sistema español muestra menor complejidad en comparación con el sistema colombiano. Efectivamente, un daño que conlleva a un perjuicio deberá ser indemnizado de forma integral, siempre que se cumpla con que se trate de un perjuicio (I) cierto (II) evaluable económicamente (III) individualizado. Para adoptar esta estructura en Colombia será necesario incursionar en la implementación de criterios similares a los baremos, sin llegar al punto de tasar el perjuicio con cifras inmóviles, lo cual les otorga mayor seguridad a los intervinientes en el proceso de responsabilidad, incluyendo, desde luego, a la compañía aseguradora.

\section{LA ACCIÓN DIRECTA}

La acción directa se inspira en el derecho propio y autónomo que ostenta el tercero perjudicado contra el asegurador ${ }^{40}$. La acción directa, coincidiendo con la doctrina mayoritaria, es un mecanismo procesal de importante valor para la protección y eficacia del derecho sustancial del tercero perjudicado o víctima ${ }^{41}$.

Ahora bien, tanto en el ordenamiento español como en el colombiano, la acción directa se encuentra reconocida legalmente.

\subsection{La acción directa en el ordenamiento español}

En el derecho español la acción directa se encuentra regulada en el artículo 76 de la Ley del Contrato de Seguro ${ }^{42}$, norma cuya aplicación no se discute en el seguro de responsabilidad cuando el tomador es la Administración Pública ${ }^{43}$. De la citada norma se resaltan tres elementos, a saber:

\footnotetext{
40 Baillo y Morales-Arce, Jaime. La acción directa en el seguro obligatorio de responsabilidad civil automovilística. Publicaciones del Real Colegio de España. Bolonia 2000, p. 41.

${ }^{41}$ Dentro de los beneficios más destacados que otorga el ejercicio de la acción directa se encuentran: "La aplicación de esa acción directa al seguro de responsabilidad civil, hará más efectiva la indemnización de la víctima, el resarcimiento rápido del daño sufrido, y la pronta disponibilidad de medios para quienes, habiendo recibido injuria física que los incapacita temporaria o definitivamente para el trabajo o perdido el jefe de familia que aseguraba su sustento, hallan en la indemnización paliativo del mal que les permitirá encontrar, o crear, el remedio de esa situación". HALPERIN, Isaac. La acción directa de la víctima contra el asegurador del responsable civil del daño, editorial La Ley, Buenos Aires, 1944, p. 9.

42 España, Ley N ${ }^{\circ}$ 50de 1980, de 8 de octubre, de Contrato de Seguro. BOE de 17 de octubre de 1980. Art. 76. "El perjudicado o sus herederos tendrán acción directa contra el asegurador para exigirle el cumplimiento de la obligación de indemnizar, sin perjuicio del derecho del asegurador a repetir contra el asegurado, en el caso de que sea debido a conducta dolosa de éste, el daño o perjuicio causado a tercero. La acción directa es inmune a las excepciones que puedan corresponder al asegurador contra el asegurado. El asegurador puede, no obstante, oponer la culpa exclusiva del perjudicado y las excepciones personales que tenga contra éste. A los efectos del ejercicio de la acción directa, el asegurado estará obligado a manifestar al tercero perjudicado o a sus herederos la existencia del contrato de seguro y su contenido".

${ }^{43}$ Concretamente, el art.36 de la Ley $\mathrm{N}^{\circ} 40$ de 2015 dispone que:

“[...] los particulares exigirán directamente a la Administración Pública correspondiente las indemnizaciones por los daños y perjuicios causados por las autoridades y personal a su servicio".

No obstante, la normativa administrativa no se refiere en ningún momento al art. 76 de la Ley de Contrato de Seguro, por lo que entendemos que este artículo también es aplicable al caso de las compañías
} 
(I)

El legitimado por activa en la acción directa es tanto el tercero perjudicado como sus herederos.

(II) Se reconoce la acción de repetición del asegurador contra el asegurado.

(III) Frente a la acción directa no proceden las excepciones que el asegurador pueda formular contra el asegurado, en virtud del contenido propio del contrato de seguro.

En ampliación del último punto sobre las excepciones oponibles al asegurado debe citarse el artículo 76 de la Ley de Contrato de Seguro que establece:

"La acción directa es inmune a las excepciones que puedan corresponder al asegurador frente al asegurado. El asegurador puede, no obstante, oponer la culpa exclusiva del perjudicado y las excepciones personales que tenga contra éste. A los efectos del ejercicio de la acción directa, el asegurado estará obligado a manifestar al tercero perjudicado o a sus herederos la existencia del contrato de seguro y su contenido".

Sin embargo, las excepciones oponibles no se limitan a las descritas en la norma citada, también se adicionan las siguientes: (I) Excepciones derivadas de la ausencia de responsabilidad civil del asegurado (II) excepciones personales entre el asegurador y el perjudicado (III) las llamadas excepciones objetivas, como la inexistencia del contrato de seguro o su terminación.

Así mismo, es clara la diferencia entre el derecho propio que tiene el tercero perjudicado para exigirle a la aseguradora el pago de la indemnización, en virtud de la acción directa, y el derecho del tercero a exigir del asegurado, causante del daño, el pago de la indemnización.

Esta diferencia se encuentra justificada por una multiplicidad de fundamentos jurídicos sobre los cuales se edifica una y otra acción, sin embrago, para no extendernos, se resalta uno de los efectos más notorios de la disimilitud de las referidas acciones, el cual se concreta en que mientras el asegurado debe concurrir a la indemnización integral del daño, la aseguradora tan solo debe hacerlo en los términos y condiciones pactadas en el contrato de seguro, entendiendo que la parte faltante debe ser atendida por el propio agente dañador, dejando incólume el principio de indemnización integral ${ }^{44}$.

Ahora bien, se pretende abordar en el presente aparte la dificultad dada al momento de la demanda que se formula en acción directa ante la jurisdicción civil, como quiera

\footnotetext{
aseguradoras de responsabilidad patrimonial de la Administración. Por ello, podemos avanzar ya que consideramos que la acción directa contra la compañía aseguradora de la Administración Pública es válida y, además, es una opción eficiente. Arquillo Colet, Begoña. Seguro de responsabilidad patrimonial de la Administración. Los problemas del aseguramiento de la responsabilidad civil de las administraciones públicas y sus soluciones jurídicas, Tesis doctoral, Barcelona, 2006, p. 139.

44 Gamero CASAdo, Eduardo. "El aseguramiento de la responsabilidad patrimonial de la Administración", capítulo IV del Tomo I, p. 36. En: La responsabilidad patrimonial de la Administración Pública. Estudio General y hábitos sectoriales. Ed. Tirant lo Blanch. Director Tomás Quintana López. Coordinadora Anabelén Casares Marcos.
} 
que el asegurador es un ente privado sujeto al derecho civil, generando que se desplacen al orden jurisdiccional civil los pleitos de responsabilidad de la Administración ${ }^{45}$.

En este sentido, y siguiendo a HUERGo, deben recordarse un par de pronunciamientos de la Sala Especial de Conflictos de Competencia del Tribunal Supremo, que ha declarado que en aquellos casos en que la Administración Pública tiene contratado un seguro de responsabilidad civil el perjudicado puede demandar ante los Tribunales civiles no sólo al asegurador, de conformidad con el artículo 76 de la Ley del Contrato de Seguro, sino también a la Administración, vulnerando de esta forma la terminante prohibición consagrada en el artículo 2 literal [e] de la Ley 29 de 1998 "Reguladora de la Jurisdicción Contencioso-administrativa" ${ }^{46}$, por el cual se impide que la Administración sea demandada por responsabilidad extracontractual ante los Tribunales civiles.

En el mismo sentido, el auto de 27 de diciembre de 2001 de la Sala Especial de Conflictos de Competencia del Tribunal Supremo atribuyó a la jurisdicción civil la competencia para conocer de una demanda de responsabilidad presentada contra una Administración, en el caso de RENFE, que es una persona jurídica de derecho públi$\mathrm{co}^{47}$. Posteriormente, en auto de 21 de octubre de 2002, relativo también a la responsabilidad de RENFE, confirma que es la jurisdicción civil la competente para asuntos en los que, a pesar de tratarse de la Administración Pública, interviene una aseguradora, pues se trata de un ente de derecho privado ${ }^{48}$.

\footnotetext{
${ }^{45}$ Huergo Lora, Alejandro. El seguro de responsabilidad civil de las Administraciones Públicas. Universidad de Oviedo, Working Paper No. 150. Barcelona, julio de 2003.

46 España, Ley N² 29 de 1998. Art. 2. "El orden jurisdiccional contencioso-administrativo conocerá de las cuestiones que se susciten en relación con:

e) La responsabilidad patrimonial de las Administraciones públicas, cualquiera que sea la naturaleza de la actividad o el tipo de relación de que derive, no pudiendo ser demandadas aquellas por este motivo ante los órdenes jurisdiccionales civil o social, aun cuando en la producción del daño concurran con particulares o cuenten con un seguro de responsabilidad".

47 "Sin embargo, no es éste el caso que aquí se cuestiona, pues admitida la legitimación de RENFE en calidad de parte demandada, lo que justificaría la declaración de la competencia de la jurisdicción contencioso-administrativa por las razones expuestas, debe contemplarse al mismo tiempo la presencia, también como codemandada, de Mapfre Seguros Generales, Compañía de Seguros y Reaseguros, la cual no comparece en el proceso por haber concurrido a la producción del daño, circunstancia que en nada cambiaría la conclusión ya adelantada, sino como contratante de una póliza de seguro (...)”.

(...) "Sin desconocer la polémica doctrina que este singular y especialísimo supuesto ha originado, al no estar contemplada, de forma expresa, la presencia de las compañías aseguradoras en el proceso contencioso- administrativo, dada su especial naturaleza, cuando se exige la responsabilidad patrimonial de una Administración pública, lo razonable, mientras la Ley no recoja, como ha hecho con los sujetos concurrentes a la producción del daño, una llamada expresa al proceso contencioso, es mantener, en este supuesto, la tradicional y ya clásica vis attractiva de la jurisdicción civil, reconocida en el art. 9.2 de la Ley Orgánica del Poder Judicial".

48 Auto de 21 de octubre de 2002 "En definitiva, la responsabilidad patrimonial de RENFE debe ser conocida por la jurisdicción contencioso-administrativa; así lo expresó obiter dicta, el Auto de esta Sala de conflictos, de 27 de diciembre de 2001 (conflicto número 41/2001). Sin embargo, el mismo Auto, como fundamento de la parte dispositiva, mantuvo que si se demanda conjuntamente a RENFE y a una compañía aseguradora, la jurisdicción competente es la civil, ya que ésta no es coautora del daño, sino que es demandada en virtud de un contrato de seguro y no cae bajo la previsión de las normas citadas de la Ley Orgánica del Poder Judicial y de la jurisdicción contencioso-administrativa; el perjudicado no puede ser obligado a seguir dos procesos, ante dos jurisdicciones diferentes, por lo que, conforme al art. 9.2 de la Ley Orgánica del Poder Judicial, por la vis attractiva de la civil, es ésta la jurisdicción competente".
} 
El citado auto de octubre 21 de 2002 presenta varios planteamientos, reproblables por parte de la doctrina, en especial sobre el fragmento en el que se indica que el perjudicado no puede ser obligado a seguir dos procesos, ante dos jurisdicciones diferentes, por lo tanto, debe seguirse la jurisdicción civil por ser esta la competente residual.

Al respecto se ha afirmado que la citada providencia olvida que la relación entre la Administración y el asegurador no es de coautoría, sino de cobertura por parte del asegurador, dentro de los límites pactados de la responsabilidad civil de la Administración asegurada. Es decir, se trata ante todo de una relación contractual.

Por otra parte, resulta curioso, en palabras de Huergo, que el aludido auto de octubre 21 de 2002, mencione que el perjudicado no puede ser obligado a seguir dos procesos, cuando es claro que el particular no tiene ninguna necesidad de tramitar dos procesos diferentes, uno contra la Administración Pública y el otro contra su asegurador, toda vez que la responsabilidad de la Administración puede ser declarada por los Tribunales contencioso-administrativos, independientemente de que esté o no asegurada, y la misma deberá responder ante el perjudicado.

Ahora bien, entendiendo que el asegurador es un interesado en el procedimiento administrativo de responsabilidad patrimonial, puesto que su obligación condicional tiene como presupuesto la responsabilidad de la Administración Pública, debe entenderse que la aseguradora también será "parte" en el proceso contencioso-administrativo. Lo cual implica que el asegurador está legitimado para impugnar la resolución que adopte la Administración, si considera que la indemnización es excesiva, así como también es legitimado por pasiva en el recurso que interponga el tercero contra la resolución administrativa en la que se declare que no hay responsabilidad o no se esté de acuerdo con el monto fijado para la indemnización.

Claro que se debe advertir que la sentencia producto del proceso ante la jurisdicción contenciosa administrativa no puede condenar al asegurador al pago de la indemnización, pues esta solo tiene competencia para condenar a la Administración. Y remata Huergo poniendo de presente la preocupación, que compartimos, en cuento a que se cambia el orden judicial competente para conocer de los asuntos de responsabilidad patrimonial de la Administración ${ }^{49}$.

Bien, en este punto, a manera de síntesis, tenemos que la jurisprudencia se ha pronunciado en sentido de afirmar que ante una reclamación dirigida contra una aseguradora y una administración, por razón del foro de atracción, el proceso será conocido por la jurisdicción civil, razonamiento que genera preocupación en la doctrina por considerar que el entendimiento según el cual los asuntos públicos, como la responsabilidad de la Administración, tienen un régimen especial, el cual está siendo vulnerado en tanto el conocimiento de los mismos se desplace a la jurisdicción civil.

Por fortuna, la mencionada preocupación quedó resuelta con la Ley Orgánica19 de 2003 al señalar que los tribunales contencioso-administrativos "conocerán de las re-

49 Huergo Lora, Alejandro. El seguro de responsabilidad civil de las Administraciones Públicas, Universidad de Oviedo, Working Paper No. 150. Barcelona, julio de 2003. 
clamaciones de responsabilidad cuando el interesado accione directamente contra la aseguradora de la Administración, junto a la Administración respectiva". Es decir, las demandas contra la aseguradora y la Administración Pública, en conjunto, serán conocidas por el orden contencioso administrativo ${ }^{50}$.

Por otro lado, el citado fragmento de la norma fue comentado por ARQuILLo CoLET, quien al respecto indica que "se deja libre la posibilidad de ejercer separadamente la acción directa, y la jurisdicción competente es claramente la jurisdicción civil" ${ }^{1}$.

No obstante, consideramos que no es del todo clara la interpretación que Arquillo Colet hace de la norma trascrita, es más, la propia norma no es en sí misma diáfana porque a la par que menciona que será la jurisdicción Contenciosa Administrativa la competente para conocer sobre la acción directa contra la aseguradora y la Administración Pública, lo cual nos parece del todo contundente además de acertado, a letra inmediata dispone "junto a la Administración respectiva", fragmento que nos sitúa en la duda, y del cual se apega el citado autor para afirmar que cuando la acción directa se interpone de forma separada frente a la aseguradora es el orden civil el competente para su conocimiento, que insistimos, a partir de un fragmento normativo que no es claro, tampoco se nos hace clara la aludida interpretación.

Adicionalmente, existe un pronunciamiento frente a la mencionada Ley Orgánica 19 de 2003, por parte de la Audiencia Provincial de Granada, jurisdicción civil, en el siguiente sentido:

"De la regulación expuesta, se deduce el intento del legislador de no quedar resquicio alguno en materia de responsabilidad patrimonial de la Administración Pública que permita el conocimiento del asunto a otro Orden Jurisdiccional, razón por la que atribuye a la jurisdicción contencioso-administrativa, tanto el conocimiento de las acciones directas (dirigidas contra la Administración y su aseguradora), como las dirigidas contra cualquier otra entidad, pública o privada, aunque las mismas, solo de una forma indirecta, sean responsables, junto a la Administración, de los daños y perjuicios causados" ${ }^{52}$ (Se resalta).

\footnotetext{
50 España, Ley Orgánica $N^{\circ} 19$ de 2003, de 23 de diciembre. Publicada en BOE número 309.

51 ARQuillo Colet, Bergoña. Seguro de responsabilidad patrimonial de la Administración. Los problemas del aseguramiento de la responsabilidad civil de las Administraciones Públicas y sus soluciones jurídicas. Tesis doctoral, Barcelona, 2006. Quien además en abogo por la tramitación directa ante el orden civil indica: "La práctica ha demostrado que se da una respuesta más rápida a las reclamaciones por los perjudicados en el caso de que la responsabilidad de la Administración se instrumente a través de una póliza de seguro y se abaratan los elevados costes de gestión de la tramitación de un procedimiento administrativo" (...) "El perjudicado podrá ejercitar la acción directa contra la compañía aseguradora de la Administración hasta el límite de la indemnización asegurada y la jurisdicción civil conocerá de dicha acción directa.

Todo esto sin perjuicio de que la compañía aseguradora pueda ejercer un derecho de repetición contra la Administración Pública, para recuperar la cantidad pagada, en el caso de que no haya podido oponer excepciones al perjudicado que sí podría haber opuesto ante la Administración, como veremos más adelante.

No obstante, todo ello debería regularse por el Legislador, con un reconocimiento expreso de la acción directa contra el asegurador de una Administración Pública, para ofrecer con toda claridad esta opción al perjudicado, que podrá ejercitar la acción directa, si lo considera oportuno, y evitar así que los beneficios de la contratación de una póliza de seguros (rapidez en la determinación y en el pago de la indemnización, y ahorro de costes de gestión) no sean efectivos en el caso de la responsabilidad de las Administraciones Públicas".

52 Audiencia Provincial de Granada España, jurisdicción civil. Recurso de Apelación núm. 654/2011 Ponente: Sr. D Antonio Mascaró Lazcano.
} 
Lo anterior, nos orienta a pensar que si, efectivamente, el legislador no quiso dejar "resquicio alguno" por el cual pudiera filtrarse el conocimiento en materia de responsabilidad de la Administración a cualquier jurisdicción distinta a la Contenciosa Administrativa, entonces la acción directa, que en rigor es aquella que se interpone de forma exclusiva contra la aseguradora, también debe ser conocida por el orden contencioso administrativo, toda vez que el debate de fondo, que de cualquier forma se surtirá en el marco de este tipo de procesos, tendrá como centro la responsabilidad de la Administración Pública, de la cual se deriva la existencia de la obligación condicional que ha contraído la aseguradora, y sin la cual es infructuoso e inane pretender que se lleve a cabo cualquier juicio contra la aseguradora, como si hubiera sido esta la causante del daño.

No obstante, la cuestión parece tener más elementos indispensables para llegar a una conclusión acertada.

Los más recientes pronunciamientos de la doctrina, que se apartan del entendimiento planteado previamente, apuntan a indicar que frente al ejercicio separado de la acción directa contra el asegurador, cuando se está amparando la responsabilidad de la Administración Pública, se debe ejercer ante la jurisdicción civil, puesto que obligar al perjudicado a dirigirse ante la jurisdicción Contencioso administrativa obstruiría su derecho al ejercicio de la acción directa pues implica que el perjudicado deba ejercitar una acción previa ante la Administración y, posteriormente, recurrir contra la decisión de ésta, convirtiéndose en un trámite extenso y complejo ${ }^{53}$.

En la misma línea, un reciente pronunciamiento de la Audiencia Provincial de Barcelona en sentencia de febrero 16 de 2017 establece lo siguiente:

\begin{abstract}
"Atendiendo a la anterior doctrina debe desestimarse el motivo al considerar competente a la jurisdicción civil para el conocimiento de la presente Litis pues la única acción ejercitada es la prevista en el art. 76 de la LCS contra la entidad Zurich en cuanto aseguradora del servicio Catalán de Salud, dado que la actora no amplió su acción frente a éste último que actuó como mero interviniente, sin que el hecho de que previamente a interponer la demanda rectora de la presente Litis se hubiere tramitado y resuelto en vía administrativa un expediente de responsabilidad patrimonial de la administración a instancia de las perjudicadas altere la competencia de la jurisdicción civil para conocer de la reclamación formulada únicamente frente a la entidad aseguradora, en tanto que es característica (en palabras del Magistrado Sr. XiolRios) de dicha acción directa la facultad del perjudicado de reclamar conjuntamente contra el asegurado causante del daño y contra la aseguradora, o solo contra esta. Es, por tanto, un supuesto de litisconsorcio pasivo voluntario o facultativo, pues de no entenderse así, la acción directa como tal no existiría, pues su característica fundamental es la de liberar al perjudicado de ejercer su acción contra el causante del daño cuando éste está asegurado" (Se resalta) $)^{54}$.
\end{abstract}

\footnotetext{
53 Xiol Rios, Juan Antonio. El ejercicio de la acción directa frente al asegurador de la responsabilidad civil de los entes públicos y asimilados. Disponible en: http://webcache.googleusercontent. com/search? q=cache:Rt7rS1P2HhQJ:www.asociacionabogadosrcs.org/congreso/ponencias3/ PonenciaJuanAntonioXiolRios.html\&hl $=$ es\&gl $=$ co\&strip $=0 \& v w s r c=0$

${ }^{54}$ Audiencia Provincial de Barcelona España, sentencia de febrero 16 de 2017.
} 
Nos queda claro que la actual posición de la jurisprudencia y la doctrina, más allá de la interpretación de que se haga de la Ley Orgánica $N^{\circ} 19$ de 2003, es que la acción directa será conocida por la jurisdicción civil, a pesar de que se trate de la responsabilidad de la Administración Pública, lo cual, desde luego, nos suscita una multiplicidad de cuestionamientos y dudas, las cuales se esbozarán a continuación:

(I) Debe la jurisdicción civil, para resolver si la compañía aseguradora está obligada a pagar la indemnización por el daño que ha sufrido el tercero, establecer la responsabilidad de la Administración Pública y, por tanto, aplicar las normas que son propias del derecho público.

La respuesta es afirmativa, el Juez civil debe analizar la existencia de responsabilidad de la Administración asegurada y, en este sentido, el Juzgado de Primera Instancia que conozca de la acción directa frente a la aseguradora deberá examinar con carácter prejudicial, en el sentido que indica el artículo 42 de la Ley de Enjuiciamiento Civil ${ }^{55}$, si la Administración incurrió o no en responsabilidad, con arreglo al estándar de responsabilidad previsto en derecho administrativo. Lo cual no implica que se le otorgue al juez civil la competencia para declarar la responsabilidad de la Administración Pública asegurada para lo que debe seguirse el procedimiento administrativo previsto legalmente ${ }^{56}$.

Se hace énfasis en que se trata de un examen prejudicial, que solo tendrá efectos dentro del proceso civil, en cuanto a que es el orden contencioso administrativo el competente para declarar la responsabilidad de la Administración Pública.

(II) Qué procede ante un escenario en el que se profieran fallos contradictorios. Ante el cuestionamiento planteado, Juan Antonio Xiol señala que, puede solucionarse mediante el efecto prejudicial que la declaración de hechos probados ante una Jurisdicción produce respecto de la otra, por lo cual, si en el primer proceso se declararon probados determinados hechos, no podrá, en el otro proceso en curso, omitirse la declaración primigenia.

Por otra parte, el citado autor indica la posibilidad de la Administración de poder participar en el proceso civil como interviniente voluntario adhesivo, de conformidad con el artículo 13 de la Ley de Enjuiciamiento Civil ${ }^{57}$.

(III) Procede la acción de repetición contra el perjudicado a quien se le paga la indemnización como resultado del proceso civil en caso de que el Tribunal de lo Con-

\footnotetext{
55 España, Ley $N^{\circ} 1$ de 2000, de 7 de enero, "Ley de Enjuiciamiento Civil".

1. A los solos efectos prejudiciales, los tribunales civiles podrán conocer de asuntos que estén atribuidos a los tribunales de los órdenes contencioso-administrativos y social.

2. La decisión de los tribunales civiles sobre las cuestiones a las que se refiere el apartado anterior no surtirá efecto fuera del proceso en que se produzca

${ }^{56}$ Rossell Garau, Marta. La acción directa contra la aseguradora de la Administración existiendo resolución administrativa previa en materia de responsabilidad. Publicado el 22 de noviembre de 2017. Disponible en: https://www.bufetebuades.com/accion-directa-contra-aseguradora-administracion/.

57 Xiol Rios, Juan Antonio. El ejercicio de la acción directa frente al asegurador de la responsabilidad civil de los entes públicos y asimilados. Disponible en: http://webcache.googleusercontent.com/ search?q=cache:Rt7rS1P2HhQJ:www.asociacionabogadosrcs.org/congreso/ponencias3/PonenciaJuan AntonioXiolRios.html\&hl $=$ es $\& g l=$ co\&strip $=0 \&$ vwsrc $=0$.
} 
tencioso administrativo confirme que la Administración no ha incurrido en responsabilidad. Cuestión que se puede resolver por aplicación del conocido principio de la cosa juzgada, siendo improcedente la repetición contra el perjudicado, debido a que existe sentencia en firme.

(IV) Podría el perjudicado accionar en la jurisdicción Contenciosa administrativa para pretender el pago de la totalidad de su perjuicio por no haber obtenido la indemnización integral por parte de la aseguradora, por aplicación de la franquicia o deducible. La respuesta es positiva, no hay norma que prohíba iniciar ambas acciones y, más aún, cuando se debe propender por la indemnización integral.

\subsection{La acción directa en el derecho colombiano}

La acción directa contra el asegurador se encuentra regulada en el artículo 1133 del Código de Comercio $^{58}$.

La consagración de la acción directa en el ordenamiento colombiano tiene un especial fundamento en la protección de la víctima, así lo ha reconocido la jurisprudencia, en cabeza del doctor Carlos Ignacio Jaramillo, al afirmar, entre tanto que, el contrato de seguro de responsabilidad pasó de ser un contrato a favor del asegurado para convertirse en un negocio jurídico a favor de terceros ${ }^{59}$.

Ahora bien, el ejercicio de la acción directa, según la jurisprudencia del orden civil, requiere la acreditación de la existencia de póliza que cubra cuyo amparo cubra el

\footnotetext{
${ }^{58}$ Colombia. Código de Comercio art. 1133: "En el seguro de responsabilidad civil los damnificados tienen acción directa contra el asegurador. Para acreditar su derecho ante el asegurador de acuerdo con al art. 1077, la víctima en ejercicio de la acción directa podrá en un solo proceso demostrar la responsabilidad del asegurado y demandar la indemnización del asegurador".

59 "Procurando estar a tono con las nuevas realidades sociales y económicas de la vida moderna, caracterizadas, en gran medida, por un estado de cosas generador de situaciones de riesgo potencial para los asociados y, por tanto, de nuevas circunstancias que comprometen la responsabilidad civil, el legislador de 1990 estimó necesario realizar sustantivas reformas, entre otras materias, a la aseguraticia y, particularmente, al seguro de daños, en torno del cual, en el art. 84 de la Ley $\mathrm{N}^{\circ} 45$ del citado año, modificatorio del precitado art. 1127 del estatuto mercantil, consagró que esta clase de seguros "impone al asegurador la obligación de indemnizar los perjuicios patrimoniales que cause el asegurado con motivo de determinada responsabilidad en que incurra de acuerdo con la ley"; que "tiene como propósito el resarcimiento de la víctima" y que ésta, "en tal virtud, se constituye en el beneficiario de la indemnización, sin perjuicio de las prestaciones que se le reconozcan al asegurado". Adicionalmente, el art. 87 de la misma ley, que transformó el sentido del también mencionado art. 1133 ibídem, previó que "En el seguro de responsabilidad civil los damnificados tienen acción directa contra el asegurador".

"De estar antes afincado en el asegurado y en su patrimonio, así como de tener por fin cardinal la protección de uno y otro, pasó a ser un seguro medularmente centrado en la víctima y encaminado a repararle a ella el perjuicio que le hubiese sido ocasionado, tanto que se le erigió en beneficiaria de la indemnización, a lo que se agrega que el seguro migró de ser un contrato a favor del asegurado para tornarse en un negocio jurídico a favor de terceros, fundamentalmente. La naturaleza y propósito otrora únicos del contrato, dejaron de ser sus rasgos principales y si bien se conservaron en la nueva normatividad, lo fueron como cuestión complementaria, aledaña, o aún indirecta, esto es, como efecto reflejo del resarcimiento del daño, en la medida en que éste conlleva, en los términos señalados, la correlativa salvaguarda del directo responsable -asegurado-y de su patrimonio". CorTe SuPRema De Justicia de Colombia, Sala de Casación Civil, sentencia de junio 29 de 2007. M.P. Carlos Ignacio Jaramillo Jaramillo.
} 
hecho determinado y la obligación de indemnizar, debidamente cuantificada, como consecuencia de situaciones constitutivas de responsabilidad civil, las cuales determinan la ocurrencia del suceso incierto que origina el derecho del tercero perjudicado ${ }^{60}$.

Así mismo, la acción directa en el derecho colombiano, según nos ilustra el doctor Carlos Ignacio JARAMILLLO ${ }^{61}$, se caracteriza por los siguientes aspectos:

(I) $\quad \mathrm{Al}$ ser el tercero perjudicado el titular de la acción directa, esta se efectúa a nombre propio y no del asegurado.

(II) La acción directa no es autónoma, es decir, la obligación del asegurador se deriva de la responsabilidad de su asegurado, sin la cual no nace en cabeza del primero la obligación de indemnizar a la víctima.

(III) A través de la acción directa la víctima no siempre se verá indemnizada de forma integral, toda vez que la obligación de la aseguradora encuentra su límite en el deducible pactado con el asegurado.

(IV) Entre el asegurador y el asegurado no existe solidaridad.

Ahora bien, frente al discutido tema de las excepciones oponibles por parte del asegurador al tercero perjudicado, debemos hacer referencia a la norma consagrada en el artículo 1044 del Código de Comercio, la cual señala:

"Salvo estipulación en contrario, el asegurador podrá oponer al beneficiario las excepciones que hubiere podido alegar contra el tomador o el asegurado, en caso de ser éstos distintos de aquél, y al asegurado las que hubiere podido alegar contra el tomador",

norma aplicable al seguro de responsabilidad civil bajo el entendido que el tercero perjudicado se constituye en beneficiario. Sin embargo, debe definirse qué tipo de excepciones son oponibles al seguro bajo estudio, que desde luego no son las mismas que operan para el resto de las figuras aseguraticias.

Al respecto, y continuando con apoyo del doctor Carlos Ignacio Jaramillo señala que el límite objetivo para la proposición de las excepciones es el siniestro, entendiendo que no aplicarán aquellas excepciones que tengan origen en hechos posteriores al siniestro, tales como el incumplimiento del aviso de siniestro, entre otros. Adicionalmente, no podrán oponérsele a la víctima aquellas excepciones personales derivadas del comportamiento del asegurado.

Bajo el anterior entendimiento podemos afirmar, siguiendo con el citado autor, que las excepciones que se le pueden oponer al tercero perjudicado son las siguientes:

Ineficacia del contrato.

\footnotetext{
${ }^{60}$ Corte Suprema de Justicia de Colombia. Sala de Casación Civil. Sentencia del 5 de julio de 2012. M.P. Edgardo Villamil Portilla.

${ }^{61}$ Jaramillo Jaramillo, Carlos Ignacio. "La acción directa en el seguro de responsabilidad civil" en América Latina, Revista Ibero-Latinoamericana de Seguros JAVEGRAF, No. 8, Bogotá, 1996.
} 
(III) Las exclusiones de cobertura.

(IV) La prescripción de la acción directa.

(V) El impago de la totalidad de la indemnización por aplicación del deducible.

Así las cosas, se pasará a analizar lo que a nuestra consideración constituye el punto más álgido de las discusiones en torno de acción directa, esto es la vinculación o no del asegurado, máxime cuando se trata de la Administración Pública y si opera o no el foro de atracción de la jurisdicción contenciosa administrativa.

Es claro que cuando el tercero perjudicado presenta su acción contra el asegurado, Administración Pública para el caso, y contra la aseguradora, la jurisdicción competente es la contenciosa administrativa $^{62}$. No obstante, el punto de debate surge cuando la acción se dirige de forma exclusiva contra la aseguradora por medio de la referida acción directa.

En el derecho colombiano la acción directa se presenta ante la jurisdicción civil a pesar de que el asegurado sea la Administración Pública, lo cual genera diversos cuestionamientos en el mismo sentido que se expusieron en el apartado correspondiente al derecho español.

La principal preocupación es que siendo el debate de fondo la responsabilidad de la Administración Pública de la cual se parte para definir la obligación del asegurador de pagar la indemnización no es posible omitir la presencia de la Administración Pública en el interior del proceso suscitado por la acción directa.

Al respecto, parte de la doctrina en cabeza de López Blanco, indica que entre el asegurador y el asegurado no existe un litisconsorcio pasivo necesario, toda vez que no hay identidad sustancial, por lo cual la sentencia solo tendrá efectos para el demandado, en este caso el asegurador, y podrá iniciarse otro proceso en contra del asegurado, razón por la cual no se constituye un litisconsorcio necesario ${ }^{63}$.

Por otra parte, y para nuestra fortuna, autores como el doctor Carlos Ignacio Jaramillo, afirman, con total acierto, que bajo el entendido de que no puede condenarse al asegurador sin haberse establecido de forma previa la responsabilidad del asegurado, juicio que desde luego no es posible efectuar sin la presencia de este último, en procura del derecho al debido proceso y al derecho de defensa, se afirma que la presencia del asegurado, en este caso la Administración Pública, es necesaria ${ }^{64}$.

\footnotetext{
${ }^{62}$ Colombia, Código Contencioso Administrativo Art. 104. De la Jurisdicción de lo Contencioso Administrativo. La Jurisdicción de lo Contencioso Administrativo está instituida para conocer, además de lo dispuesto en la Constitución Política y en leyes especiales, de las controversias y litigios originados en actos, contratos, hechos, omisiones y operaciones, sujetos al derecho administrativo, en los que estén involucradas las entidades públicas, o los particulares cuando ejerzan función administrativa. Igualmente, conocerá de los siguientes procesos:

1. Los relativos a la responsabilidad extracontractual de cualquier entidad pública, cualquiera que sea el régimen aplicable.

${ }^{63}$ López Blanco, Hernán Fabio. Comentarios al Contrato de Seguro, Dupré Editores, Bogotá, 2005, p. 377.

64 Jaramillo Jaramillo, Carlos Ignacio. "La acción directa en el seguro de responsabilidad civil" en América Latina, Revista Ibero-Latinoamericana de Seguros JAVEGRAF, No. 8, Bogotá, 1996, pp. 149-150.
} 
Así entonces, bajo la premisa anterior, resulta claro que al vincularse a la Administración Pública al proceso civil, el juez de forma inmediata debe remitir el asunto al conocimiento de la jurisdicción Contenciosa administrativa, pues como quiera es este el juez natural del Estado y el juicio de responsabilidad que se emprende en contra suyo no puede omitirse en ningún caso siquiera en fomento de la celeridad y la facilidad para el tercero perjudicado, quien en una u otra jurisdicción recibirá garantías para obtener una indemnización integral.

\section{CONCLUSIONES}

$>\quad$ El sistema de la responsabilidad civil encuentra su justificación económica y social en la reducción y equilibrio de los costes sociales, toda vez que se incorpora este, el coste social, dentro del coste privado. Por lo tanto, el individuo que realiza la actividad tendrá incentivos para reducir los riesgos y tomar medidas preventivas, de lo contrario, será responsable patrimonialmente por los daños que cause.

Por su parte, en los sistemas de responsabilidad objetiva, los agentes dañadores con aversión al riesgo, al ser los agentes residuales, tomarán medidas excesivas y, por ende, ineficientes. Esto se resuelve a través de un sistema de seguros, dentro del cual tanto las víctimas como los agentes dañadores, que sean aversos al riesgo, contratarán un seguro y así disminuirán la incertidumbre dejando de tomar medidas excesivas e ineficientes.

El daño a la persona se puede derivar en: (I) Perjuicio patrimonial: 1.1. Daño emergente 1.2. Lucro cesante (II) Perjuicio extrapatrimonial: 2.1. Daño moral 2.2. Daño corporal (físico o psíquico). No se incorporan las demás categorías, debido a que las estimamos redundantes, y por tal razón pueden resultar en daños punitivos.

Así las cosas, consideramos que el sistema español muestra menor complejidad en comparación con el sistema colombiano. Efectivamente, un daño que conlleva a un perjuicio deberá ser indemnizado de forma integral, siempre que se cumpla con que se trate de un perjuicio (I) cierto (II) evaluable económicamente (III) individualizado. Para adoptar esta estructura en Colombia será necesario incursionar en la implementación de los baremos, que les otorgan mayor seguridad a los intervinientes en el proceso de responsabilidad, incluyendo, desde luego, a la compañía aseguradora.

$>\quad$ Finalmente, frente al último apartado debemos concluir que a pesar de tratarse de la acción directa la cual solo se dirige contra la compañía aseguradora, debe vincularse a la Administración Pública al proceso, en atención a que el asunto de fondo versa sobre la responsabilidad que se atribuye a la misma y en procura del debido proceso. Aceptando lo anterior, en razón al foro de atracción el proceso deberá redirigirse al orden Contencioso administrativo, juez natural de la administración y al cual corresponde el conocimiento de los asuntos de responsabilidad patrimonial del Estado. 


\section{BIBLIOGRAFÍA}

\section{Leyes de Colombia:}

Constitución política colombiana (1991). Asamblea Nacional Constituyente, Bogotá, Colombia, 6 de Julio de 1991.

\section{Leyes de España:}

Constitución Española. Boletín Oficial del Estado, 29 de diciembre de 1978, número 311.

Ley $\mathrm{N}^{\circ} 1$ de 2000, de 7 de enero, "Ley de Enjuiciamiento Civil”. Publicado en Boletín Oficial del Estado número 7.

Ley $\mathrm{N}^{\circ} 35 / 2015$, de 22 de septiembre, de reforma del sistema para la valoración de los daños y perjuicios causados a las personas en accidentes de circulación. Publicado en: «BOE» núm. 228, de 23 de septiembre de 2015.

\section{Jurisprudencia colombiana:}

Corte Constitucional de Colombia, sala plena, sentencia de 28 de abril de 1999, M.P. Marta Victoria Sáchica de Moncaleano.

Corte Constitucional de Colombia, sala plena, sentencia de 17 de junio de 2009, M.P. Juan Carlos Henao Pérez.

Consejo de Estado, Sala de lo Contencioso Administrativo, Sección Tercera, 11 de diciembre de 1992.

Consejo de Estado de Colombia, Sala de lo Contencioso Administrativo, Sección Tercera, Sentencia mayo 6 de 1993. C.P. Julio César Uribe Acosta.

Consejo de Estado de Colombia, Sala de lo Contencioso Administrativo, Sección Tercera, sentencia de julio 19 de 2000. C.P. Alier Eduardo Hernández Henríquez.

Consejo de Estado de Colombia, Sala de lo Contencioso Administrativo, Sección Tercera, sentencia de 15 de agosto de 2007.

Consejo de Estado de Colombia, Sala de lo Contencioso Administrativo, Sección Tercera, Sentencia de agosto 28 de 2014, C.P. Dra. Stella Conto Díaz del Castillo.

Consejo de Estado de Colombia, Sala de lo Contencioso Administrativo, Sección Tercera, sentencia de febrero 21 de 2018, C.P. Jaime Orlando Santofimio Gamboa.

Corte Suprema de Justicia de Colombia, Sala de Casación Civil, 21 de Julio de 1922, M.P. Tancredo Nannetti, Gaceta Judicial, Tomo XXIX No. 1515.

Corte Suprema de Justicia de Colombia, Sala de Casación Civil, sentencia de junio 29 de 2007. M.P. Carlos Ignacio Jaramillo Jaramillo.

Corte Suprema De Justicia de Colombia, Sala de Casación Civil, sentencia de mayo 13 de 2008. 
Corte Suprema de Justicia de Colombia, Sala de Casación Civil, sentencia 13 de mayo de 2008, M.P: Cesar Julio Valencia Copete.

Corte Suprema de Justicia de Colombia. Sala de Casación Civil. Sentencia del 5 de julio de 2012. M.P. Edgardo Villamil Portilla.

Tribunal Superior de Medellín el 22 de marzo de 1985, mediante fallo con ponencia de la Dra. Beatriz Quintero Prieto.

\section{Jurisprudencia española:}

Tribunal Supremo de España, sentencia de diciembre 26 de 1986.

Tribunal Supremo de España, sentencia de junio 15 de 1995.

Audiencia Provincial de Granada España, jurisdicción civil. Recurso de Apelación núm. 654/2011 Ponente: Sr. D Antonio Mascaró Lazcano.

Audiencia Provincial de Barcelona España, sentencia de febrero 16 de 2017.

\section{Doctrina:}

ARQuillo Colet, Begoña. Seguro de responsabilidad patrimonial de la Administración. Los problemas del aseguramiento de la responsabilidad civil de las administraciones públicas y sus soluciones jurídicas, Tesis doctoral dirigida por Pablo Salvador Coderch (dir. tes.). Universitat Pompeu Fabra, Barcelona, 2007.

Baillo y Morales-Arce, Jaime. La acción directa en el seguro obligatorio de responsabilidad civil automovilística. Publicaciones del Real Colegio de España. Bolonia 2000.

De Cupis, Adriano. Teoría General de la Responsabilidad Civil, El Daño, 2 ed. Barcelona: BOSCH, Casa Editorial, 1975.

FLóRez Fernández, José Gregorio. El daño y la responsabilidad en el derecho norteamericano, Universidad Externado de Colombia, Bogotá, 2001.

Gamero CAsAdo, Eduardo. "El aseguramiento de la responsabilidad patrimonial de la Administración", capítulo IV del Tomo I. En: La responsabilidad patrimonial de la Administración Pública. Estudio General y hábitos sectoriales. Ed. Tirant lo Blanch. Director Tomás Quintana López. Coordinadora Anabelén Casares Marcos.

Grijalba LóPez, Juan Carlos. La compañia aseguradora en el procedimiento de responsabilidad patrimonial. Dialnet, DS: Derecho y salud, ISSN 1133-7400, Vol. 21, Nº. Extra-1, 2011 (Ejemplar dedicado a: XIX Congreso "Derecho y Salud").

Gómez Pomar, Fernando, Daño moral, Indret: Revista para el Análisis del Derecho, ISSN 1698-739X, No. 1, 2000.

Huergo Lora, Alejandro. El seguro de responsabilidad civil de las Administraciones Públicas, Universidad de Oviedo, Working Paper No. 150. Barcelona, julio de 2003. 
JARAMILlo JARAmiLlo, Carlos Ignacio. "La acción directa en el seguro de responsabilidad civil” en América Latina, Revista Ibero-Latinoamericana de Seguros JAVEGRAF, No. 8, Bogotá, 1996.

JARAmillo JaRAmillo, Carlos Ignacio. Los deberes de evitar y mitigar el daño Editorial Temis, Pontificia Universidad Javeriana, Bogotá, 2013.

Lagomarsino, Ismael A. Consorcio de Propietarios Juncal 2259/61, La Ley, 1997. En WeinGarten, Celia. Manual de derecho de daños, La Ley, Buenos Aires, 2010.

López Blanco, Hernán Fabio. Comentarios al Contrato de Seguro, Dupré Editores, Bogotá, 2005.

Maciá Gómez, Ramón. Concepto y evaluación del daño moral, 19 de enero de 2009 http:// www.ramonmacia.com/el-dano-moral-concepto-elementos-y-valoracion/.

Martín-Casals, Miquel. Principios de Derecho Europeo de la Responsabilidad Civil, traducción de REDPEC, Editorial Aranzadi S.A., 2008.

PAPAYANIS, Diego. La responsabilidad civil como asignación de pérdidas, Revista InDret, Barcelona, enero 2014.

Pavelek, Juan Eduardo, El aseguramiento de la responsabilidad de la Administración. Revista de derecho de los seguros privados.

Peirano, Jorge. Responsabilidad extracontractual, Ed. Temis, Bogotá, 1981.

Rossell Garau, Marta. La acción directa contra la aseguradora de la Administración existiendo resolución administrativa previa en materia de responsabilidad. Publicado el 22 de noviembre de 2017. Disponible en: https://www.bufetebuades.com/accion-directa-contra-aseguradora-administracion/.

Valdivieso, María Juliana. Asuntos: Legales "¿Cómo se clasifica el perjuicio inmaterial en Colombia, actualmente?", 30 de enero de 2019 https://www.asuntoslegales.com. co/consultorio/como-se-clasifica-el-perjuicio-inmaterial-en-colombia-actualmente-2821836.

Velásquez Posada, Obdulio. Itinerario Jurisprudencial del Daño Moral en Colombia. Revista Responsabilidad Civil y del Estado No. 26.

VeIga Copo, Abel B. Tratado del contrato de seguro, Editorial Aranzadi, S.A.U., Navarra, 2017.

Weingarten, Celia. Manual de derecho de daños, La Ley, Buenos Aires, 2010.

Xiol Rios, Juan Antonio. El ejercicio de la acción directa frente al asegurador de la responsabilidad civil de los entes públicos y asimilados. Disponible en: http://webcache. googleusercontent.com/search?q=cache:Rt7rS1P2HhQJ:www.asociacionabogadosrcs.org/congreso/ponencias3/PonenciaJuanAntonioXiolRios.html\&hl=es\&gl=co\&strip $=0 \&$ vwsrc $=0$. 
